03.1

\title{
Экспериментальное исследование нового способа уменьшения волнового сопротивления профиля при трансзвуковых скоростях
}

\author{
(C) М.А. Брутян ${ }^{1,2}$, А.В. Волков ${ }^{1,2}$, А.В. Потапчик ${ }^{1}$ \\ ${ }^{1}$ Центральный аэрогидродинамический институт им. проф. Н.Е. Жуковского, Жуковский, Московская обл., Россия \\ ${ }^{2}$ Московский физико-технический институт (Национальный исследовательский университет), Долгопрудный, Московская \\ обл., Россия \\ E-mail: m_brut@mail.ru
}

Поступило в Редакцию 30 сентября 2019 г.

В окончательной редакции 23 марта 2020 г.

Принято к публикации 25 марта 2020 г.

Предложен новый способ уменьшения волнового сопротивления профиля при трансзвуковых скоростях, который связан с организацией в местной сверхзвуковой зоне участка микроволнистой верхней поверхности. Проведены весовые и физические исследования исходного и модифицированного профилей. Экспериментально установлено, что предлагаемая реализация нового подхода приводит к образованию системы слабых волн сжатия, постепенному торможению сверхзвукового потока, уменьшению числа Маха перед замыкающим скачком уплотнения и, как следствие, к ослаблению его интенсивности и уменьшению волнового сопротивления.

Ключевые слова: трансзвуковые течения, экспериментальные исследования, уменьшение волнового сопротивления.

DOI: 10.21883/PJTF.2020.12.49525.18054

К настоящему времени в мире эволюционным путем сложился традиционный облик классической схемы пассажирских самолетов, рассчитанных на трансзвуковые скорости крейсерского полета. Для заметного прорыва в области проектирования летательных аппаратов (ЛА) такого класса нужны новые концепции, в основе которых лежат идеи управления обтеканием с целью уменьшения сопротивления и тем самым повышения аэродинамического совершенства ЛА при трансзвуковых режимах крейсерского полета [1].

Основными составляющими сопротивления ЛА на трансзвуковых скоростях являются сопротивление трения, индуктивное сопротивление, а также волновое сопротивление, вызванное скачком уплотнения. Первые две компоненты общего сопротивления имеют место во всем диапазоне скоростей полета, и традиционные способы их уменьшения хорошо известны [2-7]. Что касается волнового сопротивления, то оно возникает при больших трансзвуковых скоростях и является причиной резкого возрастания общего сопротивления ЛА, что при определенных условиях может привести к явлению бафтинга - сильной тряске, которая из-за усталости конструкции может даже вызвать разрушение крыла. Поэтому поиск способов уменьшения волнового сопротивления и ослабления трансзвукового бафтинга является актуальной задачей прикладной аэродинамики [8-12]. Решение этих задач открывает новые возможности для улучшения аэродинамических характеристик крыла и летательного аппарата в целом.

В настоящей работе представлены результаты экспериментальных исследований нового способа управления обтеканием, который приводит к ослаблению интенсивности скачка уплотнения и связанного с ним отрыва пограничного слоя. Новая концепция основана на уменьшении числа Маха $\mathrm{M}_{1}$ перед скачком уплотнения путем постепенного торможения сверхзвукового потока. Для ее осуществления предлагается способ, заключающийся в том, что в области расположения местной сверхзвуковой зоны создается участок микроволнистой поверхности крыла, который вызывает появление ряда слабых волн сжатия. Наличие последовательности косых скачков уплотнения малой интенсивности приводит к постепенному торможению сверхзвукового потока, уменьшению числа $\mathrm{M}_{1}$ перед основным скачком и, как следствие, к ослаблению его интенсивности и уменьшению волнового сопротивления крыла.

Эксперименты проводились с фиксацией ламинарнотурбулентного перехода на $10 \%$ хорды модели профиля в диапазоне чисел Рейнольдса $\operatorname{Re}=(2.3-2.8) \cdot 10^{6}$ и чисел $\mathrm{M}_{\infty}=0.6-0.8$ в трансзвуковой аэродинамической трубе Т-112 ЦАГИ. Модель выполнена в виде прямоугольного крыла с хордой $200 \mathrm{~mm}$ и размахом $599 \mathrm{~mm}$. Сечение крыла соответствовало геометрии сверхкритического профиля П-184-15 максимальной относительной толщины $15 \%$. Верхняя и нижняя стенки рабочей части трубы перфорированы. Боковые стенки не перфорированы и имеют оптические окна, между которыми с помощью специальных кронштейнов устанавливается модель, что позволяет проводить оптические исследования картины обтекания одновременно с весовыми измерениями на трехкомпонентных аэродинамических весах. Обработка результатов весовых измерений проводилась по стандартной методике с внесением поправок на обдув рамы весов. Оптические исследования 


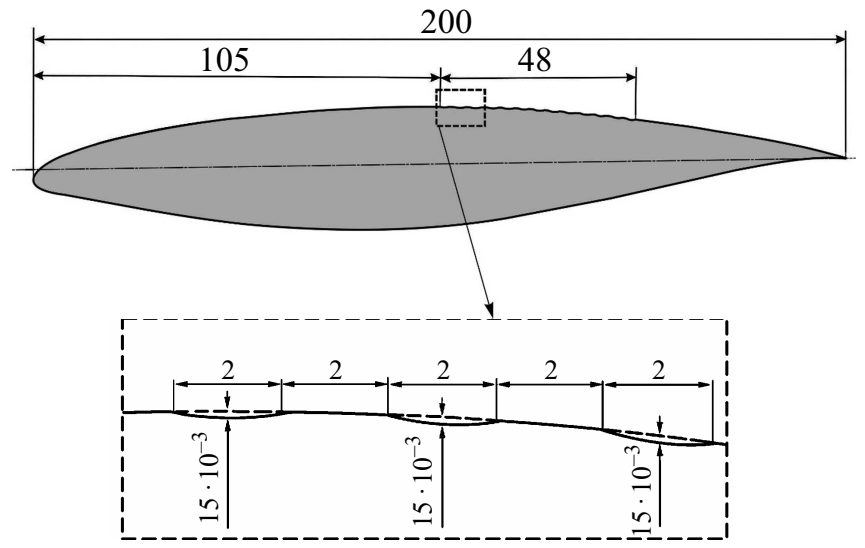

Рис. 1. Модель профиля крыла с участком микроволнистой поверхности.

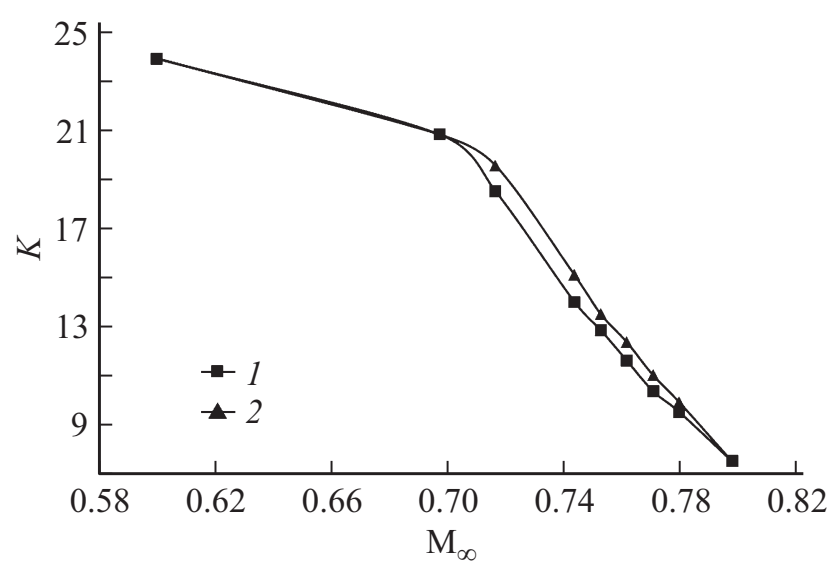

Рис. 2. Экспериментальные зависимости аэродинамического качества от числа Маха набегающего потока при угле атаки $\alpha=4^{\circ} .1-$ исходный профиль, 2 - профиль с участком микроволнистой верхней поверхности.

выполнялись прямотеневым методом с дефокусировкой на расстоянии $460 \mathrm{~mm}$ от торца модели. Визуализация картины обтекания модели осуществлялась с использованием импульсной лампы высокой яркости, что дало возможность регистрировать вихревые структуры, возникающие при взаимодействии скачка уплотнения с пограничным слоем.

Эффективность нового способа управления обтеканием проверялась в экспериментах на модифицированной модели сверхкритического профиля П-184-15. Модификация состояла в том, что на участке верхней поверхности модели в местной сверхзвуковой зоне была выполнена микроволнистость, геометрические параметры которой в миллиметрах указаны на рис. 1 .

Эксперименты проводились с регистрацией оптической картины обтекания, сопровождаемой скоростной видеорегистрацией и весовыми измерениями аэродинамических характеристик. Результаты, полученные при исследовании модели с участком микроволнистой поверхности, сопоставлялись с результатами испытаний исходной немодифицированной модели. Наиболее полно физическая картина обтекания микроволнистой поверхности модели профиля была изучена при угле атаки $\alpha=4^{\circ}$. Выбор данного угла связан с тем, что, как показали проведенные ранее исследования, при этом угле атаки реализуется значение коэффициента подъемной силы, характерное для крейсерского (наиболее экономичного) режима полета ЛА типа крылатой ракеты.

Экспериментальные зависимости аэродинамического качества $K$ исходного и модифицированного профиля П-184-15 от числа $\mathrm{M}_{\infty}$ приведены на рис. 2. Видно, что в диапазоне чисел Маха от 0.7 до 0.78 значения $K$ у модифицированного профиля выше, чем у исходного. Наибольший прирост $(\Delta K \approx 0.5-1.0)$ наблюдается при умеренных числах $\mathrm{M}_{\infty} \approx 0.72-0.76$, когда значение числа Маха перед замыкающим местную сверхзвуковую зону скачком уплотнения находится в интервале $\mathrm{M}_{1} \approx 1.25-1.30$. Фотография характерной картины течения в области расположения скачка уплотнения для модифицированного профиля приведена на рис. 3. На оптическом снимке хорошо видны основной скачок уплотнения, замыкающий местную сверхзвуковую зону, и образовавшаяся на микроволнистом участке поверхности система косых волн сжатия. Вертикальная линия на снимке является изображением расположенной в плоскости фокусировки юстировочной нити, которая необходима для настройки теневого оптического прибора.

На основании результатов, полученных в ходе проведенных экспериментальных исследований, можно сделать вывод, что наличие последовательности косых скачков уплотнения малой интенсивности в местной сверхзвуковой зоне на верхней поверхности профиля приводит к уменьшению числа Маха перед замыкающим скачком уплотнения. По предварительным расчетам, сделанным на основании численного решения осредненных по Рейнольдсу уравнений Навье-Стокса, это умень-

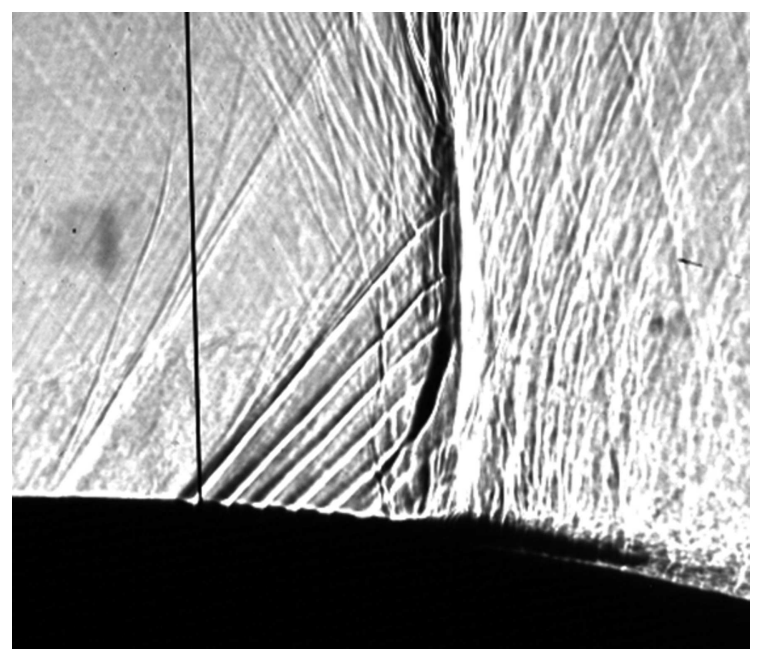

Рис. 3. Оптическая картина обтекания верхней модели профиля с участком микроволнистой верхней поверхности. $\mathrm{M}_{\infty}=0.76$. 
шение составляет $\Delta \mathrm{M}_{1} \approx 0.01-0.02$. Данный эффект вызывает ослабление интенсивности скачка уплотнения и вихревых структур за ним, которые влияют на характер течения в пограничном слое за скачком уплотнения. Экспериментально установлено, что в диапазоне умеренных чисел $\mathrm{M}_{\infty}$ указанные эффекты приводят к уменьшению волнового сопротивления и увеличению аэродинамического качества профиля.

\section{Финансирование работы}

Работа выполнена за счет гранта Российского научного фонда (проект № 16-19-10407).

\section{Конфликт интересов}

Авторы заявляют, что у них нет конфликта интересов.

\section{Список литературы}

[1] Брутян М.A. Задачи управления течением жидкости и газа. М.: Наука, 2015. 271 с.

[2] Dimitropoulos C.D., Dubief Y., Shaqfeh E.S., Moin P., Lele S. // Phys. Fluids. 2005. V. 17. P. 011705. https://doi.org/10.1063/1.1829751

[3] Walsh M.J. // AIAA J. 1983. V. 21. P. 485-486. https://doi.org/10.2514/3.60126

[4] Bushnell D.M., Moor K.J. // Annu. Rev. Fluid Mech. 1991. V. 23. N 1. P. $65-79$. https://doi.org/10.1146/annurev. fluid. 23.010191.000433

[5] Корнилов В.И. // Теплофизика и аэромеханика. 2005. Т. 12. № 2. C. $183-208$.

[6] Коновалов С.В., Лашков Ю.А., Михайлов В.В. // Изв. РАН. Механика жидкости и газа. 1998. № 1. С. 163-168.

[7] Баранов П.А., Исаев С.А., Пригородов Ю.С., Судаков А.Г. // Письма в ЖТФ. 1998. Т. 24. В. 17. С. 16-23.

[8] Брутян М.А., Волков А.В., Потапчик А.В. // Письма в ЖТФ. 2019. Т. 45. В. 21. C. 19-21.

[9] Malton P., Dandois J., Lepage A., Brunet V., Bur R. // AIAA J. 2013. V. 51. P. 761-772. https://doi.org/10.2514/1.j051000

[10] Gao C.Q., Zhang W.W., Kou J.Q. // J. Fluid. Mech. 2017. V. 824. P. 312-351. https://doi.org/10.17/jfm.2017.344

[11] Giannelis N.F., Vio G.A., Levinski O. // Prog. Aerosp. Sci. 2017. V. 92. P. 32-84. https://doi.org/10.1016/j.paerosci

[12] Abramova K.A., Brutyan M.A., Lyapunov S.V., Petrov A.V., Potapchik A.V., Ryzhov A.A., Soudakov V.G. Investigation of buffet control on transonic airfoil by tangential jet blowing // 6th Eur. Conf. for aeronautics and space sciences (EUCASS). Krakov, 2015. P. 1-9. 